\title{
Radiological Study on the Anatomical Site and Size of Ureteric Calculi: A Retrospective Study
}

\section{ABSTRACT}

Introduction: Ureteric stones are said to lodge most commonly at the narrowest anatomical areas of the ureter. The site of pain depends on the location of the calculi. Spontaneous passage of ureteric stones is influenced by size, location and laterality of the stones.

Aim: To investigate the size and location of ureteric stones.

Materials and Methods: This was a retrospective study of 72 patients in whom urinary stones were diagnosed by computed tomography between January 2018 and July 2019. The size of the ureteric stones was measured by its maximal width on Computed Tomography (CT) and location of the stones was also determined. The diameter of both the ureters were ascertained at the widest portion. Statistical analysis was performed using SPSS version 23. Descriptive data was presented as percentage and mean while comparative analysis was done using Student's t-test.
Results: The average patient age was $41 \pm 12.4$ years (range, 1770 years) affecting 42 (58.33\%) males and 30 females $(41.77 \%)$. The ureteric stones were localized at the VUJ in 30 cases $(41 \%)$, at the distal ureter in $11(15 \%)$, at the level of external iliac vessel in 3 cases (5\%), at the proximal part in 19 (27\%) and at the PUJ in 9 cases (12\%). Calculi were identified more often on the right ureter (44 cases, $61.2 \%$ ) than the left (28 cases, $38.8 \%)$. The average diameter of the ureter on the right and left was $3.46 \mathrm{~mm}$ (range, 1.8-4.7 $\mathrm{mm}$ ), and $3.33 \mathrm{~mm}$ (range, 2.1$5.5 \mathrm{~mm}$ ) respectively. There was no significant difference in the mean diameter of the ureteric stones of both the sides at the corresponding levels of the ureter. The smaller the stones, the closer to the VUJ were they located.

Conclusion: This study provides an insight into the anatomy of the ureter and would be essential for selection of appropriate line of intervention and treatment modality.

\section{INTRODUCTION}

The ureters are tubular structures which begin at the Pelviureteric Junction (PUJ). They descend into the abdomen where they are related anterior to the psoas major and then enter the urinary bladder at the Vesicoureteric junction (VUJ). The peristalsis rendered by the smooth muscle wall of the ureter, aids the passage of urine. The $\mathrm{PUJ}$, the VUJ, and the region of the ureter crossed by the common iliac arteries are sites which tend to lodge the renal stones.

Ureteric calculi lie within the ureter between the PUJ to the VUJ. The site of pain is related to depends on the location of the calculi. Patients with stones in the PUJ may complain of flank pain. Pain due to stones in the proximal and distal part of the ureter may be referred to the lumbar and groin region respectively. Calculus in the middle part of the ureter may simulate an appendicitis or diverticulitis.

A plain abdominal Kidney Urinary Bladder (KUB) X-ray can readily spot a large radiopaque calculi. However, their role is limited in the detection of smaller calculi and radiolucent stones and in the assessment of hydronephrosis. Moreover, bowels shadows can also mask the presence of a calculus. Therefore, Non-contrast CT (CT KUB) is the best imaging tool.

Information on the stone size and site is vital in deciding the appropriate line of management. Textbooks of Anatomy have stated that ureteral stones frequently occur at the uretero-pelvic junction (UPJ), the ureter at the crossing external iliac vessel (UEIV) and the uretero-vesical junction (UVJ) [1,2].

Spontaneous passage and expulsion of ureteral stones is influenced by the size, location and laterality of the stones [3,4,5]. Hence,this study was designed to investigate the location of ureteral stones and the ureteral diameter in patients with renal colic.

Hence the study compared the mean diameter of the ureteric stones on both the sides at the corresponding levels of the ureter,to ascertain the prevalence of ureteric stones in different age groups and to compare the mean diameter of the ureteric stones in males and females. The aim of the study is to investigate the size and location of ureteric stones.

\section{MATERIALS AND METHODS}

This was a retrospective cross-sectional study conducted at Shri Sathya Sai Medical College and Research Institute between January 2018 and July 2019. The study was conducted among 411 patients who presented to the Department of General Surgery with complaints of abdominal pain. After obtaining Institutional Ethical Committee clearance (IEC 2019/556).

The sample size $(n)$ was calculated using the formula $n=\left(z_{1-\alpha / 2}\right)^{2}(p)$ (q) $/ d^{2}=72$

where, $z_{1-\alpha / 2}=1.96, p=0.06, q=1-p, d$ (precision) $=0.05$

A non-contrast computed tomography had been performed in these patients by using a helical scanner. Image review was performed at a Picture Archiving and Communication System (PACS) workstation. The calculi were analysed by multiplanar reformatting in the coronal reformat [Table/Fig-1] [6]. Stone size estimation with measurement of the maximal width was performed as it is the most important predictor of spontaneous stone passage [7]. The diameter of both the ureters were ascertained at the widest part.

The location of the ureteric stones was delineated as follows:

I. PUJ (Pelviureteric Junction)

II. Proximal ureter

III. UEIV (Ureter at the level of external iliac vessels)

IV. Distal ureter

V. VUJ (Vesicoureteric junction) 


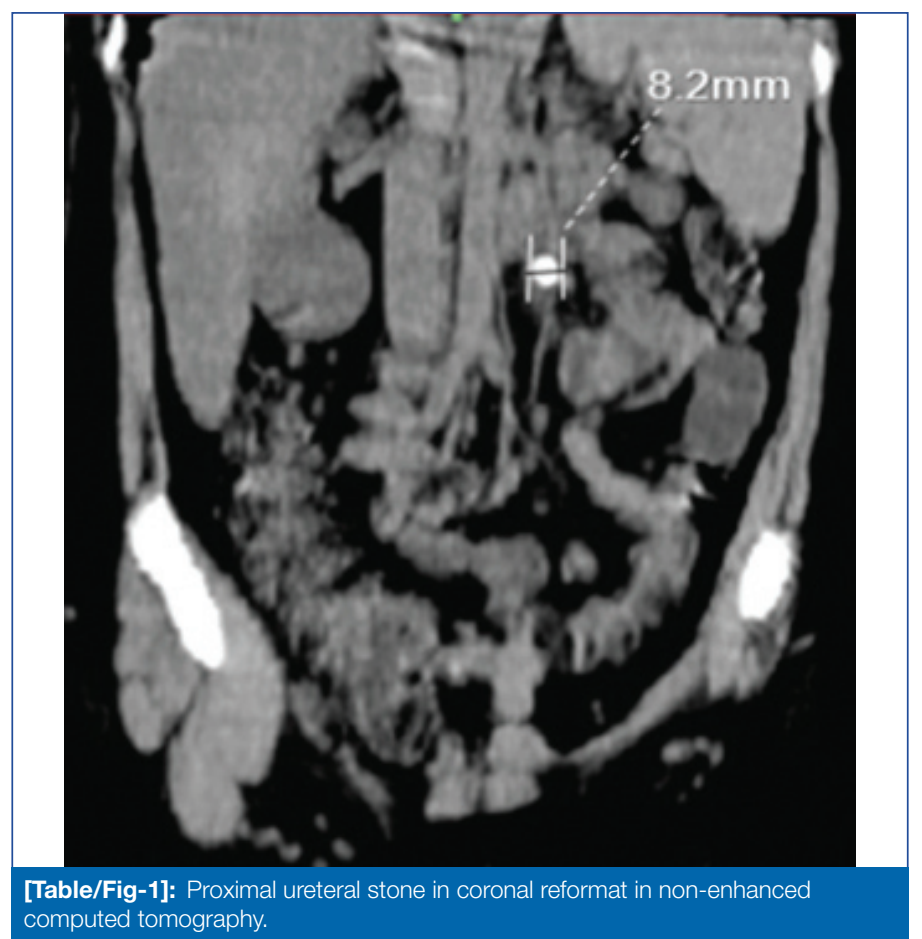

The proximal ureter represented the distance between the PUJ and the UEIV. The distal ureter represented the interval between the UEIV and the UVJ. The diameter of the ureters was ascertained at the widest part.

Inclusion criteria: Patients who came to the Department of General Surgery aged more than 12 years and were diagnosed with ureteric calculi on non-CT of Kidney Urinary Bladder were included.

Exclusion criteria: Patients with prior history of renal, anomalies like neurogenic bladder and stricture urethra were excluded.

\section{STATISTICAL ANALYSIS}

Student's t-test was employed for statistical analysis with SPSS version 23 to ascertain the difference in the mean diameter of the ureteric stones of both the sides at the corresponding levels of the ureter. It was also used to determine the difference in the mean diameter of the ureteric stones in male and female.

\section{RESULTS}

The average age of the patient was $41 \pm 12.4$ years (range 17-70) affecting 42 (58.33\%) males and 30 females (41.77\%). The peak incidence of ureteric stones in males and females was in the age group 41-50 years and 51-60 years, respectively [Table/Fig-2]. The variation in the mean size of the ureteric stones among male and female was insignificant $(p=0.933)$ [Table/Fig-3]. The calculi were identified more on the right ureter (44 cases, 61.2\%) than the left (28 cases, 38.8\%). Sexual dimorphism in the mean diameter of the Right ureter, 3.46 $\pm 0.6 \mathrm{~mm}$ (range, 1.8-4.7 mm), and Left ureter, $3.33 \pm 0.8 \mathrm{~mm}$ (range, 2.1-5.5 mm), was insignificant ( $p=0.25)$. Renal calculi were frequently found in association with ureteric calculi in one third of the cases (23 cases, 33.3\%) usually on the same side (19 cases) and at times bilateral (4 cases).

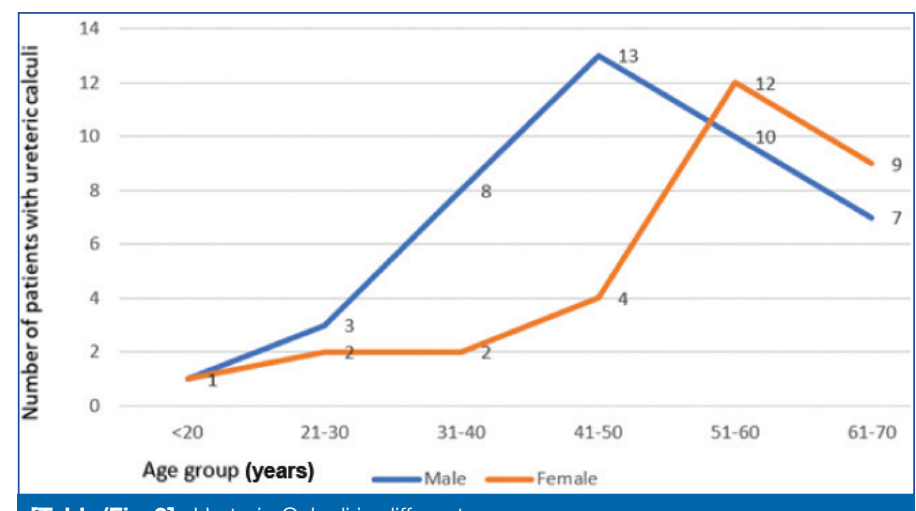

[Table/Fig-2]: Ureteric Calculi in different age groups.

Amongst the 72 patients investigated, the ureteric stones were located at the VUJ in 30 patients (41\%), [Table/Fig-4], at the distal ureter in 11 (15\%) and at the UEIV in 3 (5\%) [Table/Fig-5], at the proximal ureter in 19 patients (27\%) [Table/Fig-6] and at the PUJ in 9 (12\%) [Table/Fig-7].

The stone size ranged between $4-18 \mathrm{~mm}$ with an average size of $10.1 \pm 8.2 \mathrm{~mm}$ at the PUJ, $6.8 \pm 3.23 \mathrm{~mm}$ (range, $3-15 \mathrm{~mm}$ ) at the proximal ureter, $6.1 \pm 2.81 \mathrm{~mm}$ at the UEIV (range $4-8 \mathrm{~mm}$ ), $4.56 \pm 1.73 \mathrm{~mm}$ (range $1-10 \mathrm{~mm}$ ) at the distal ureter and $3.33 \pm 1.82 \mathrm{~mm}$ (range, $1-8 \mathrm{~mm}$ ) at the VUJ. A comparison of the mean size of ureteric stones between the two sides is enlisted in [Table/Fig-8]. The smaller the stones, the more distally they are located in the ureter [Table/Fig-9].

\begin{tabular}{|c|c|c|c|c|c|c|c|c|}
\hline \multirow[b]{2}{*}{ Sex } & \multirow[b]{2}{*}{ Mean $(\mathrm{mm})$} & \multirow[b]{2}{*}{ Std. deviation $(\mathrm{mm})$} & \multirow[b]{2}{*}{ ts } & \multirow[b]{2}{*}{$\mathrm{p}$-value } & \multirow[b]{2}{*}{ Mean difference } & \multirow[b]{2}{*}{ Std. error difference } & \multicolumn{2}{|c|}{$95 \%$ confidence interval of difference } \\
\hline & & & & & & & Lower & Upper \\
\hline Male & 6.238 & 2.424 & \multirow{2}{*}{0.0863} & \multirow{2}{*}{0.9333} & \multirow{2}{*}{6.10} & \multirow{2}{*}{0.40667} & \multirow{2}{*}{3.223} & \multirow{2}{*}{10.114} \\
\hline Female & 6.102 & 2.554 & & & & & & \\
\hline
\end{tabular}
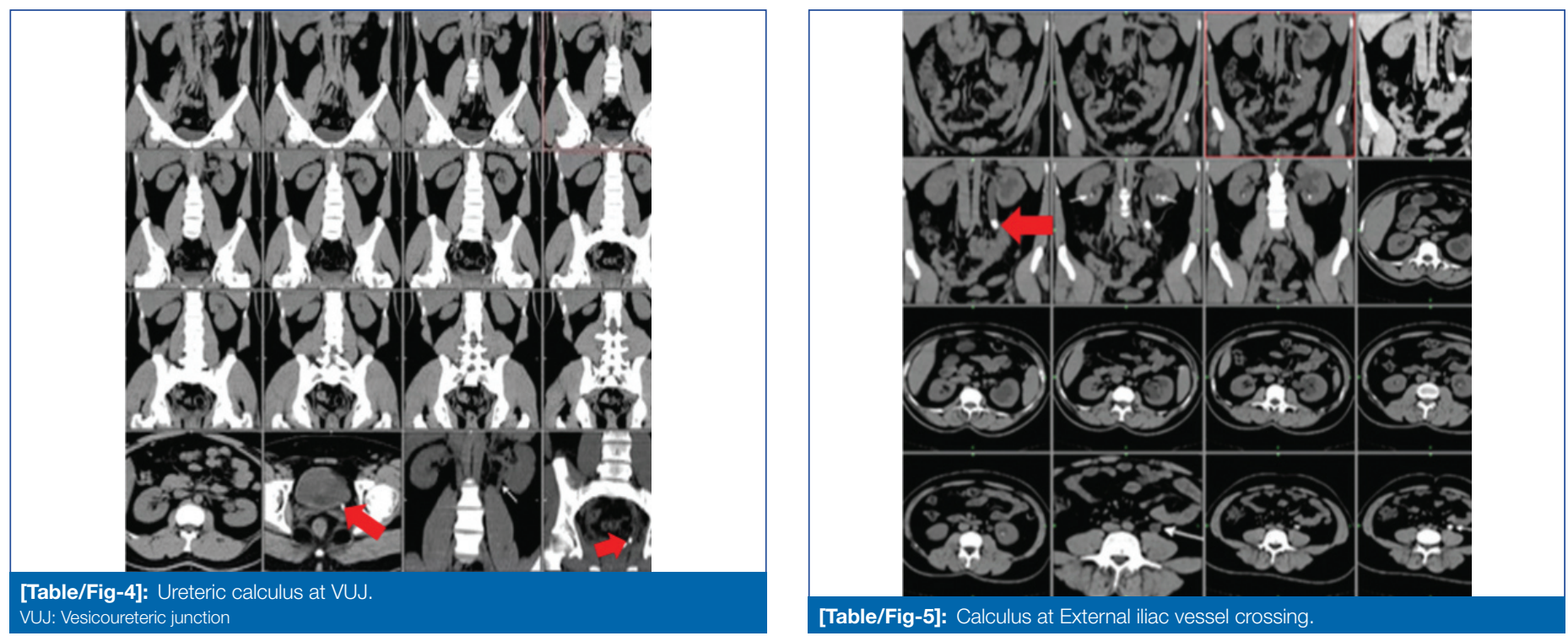

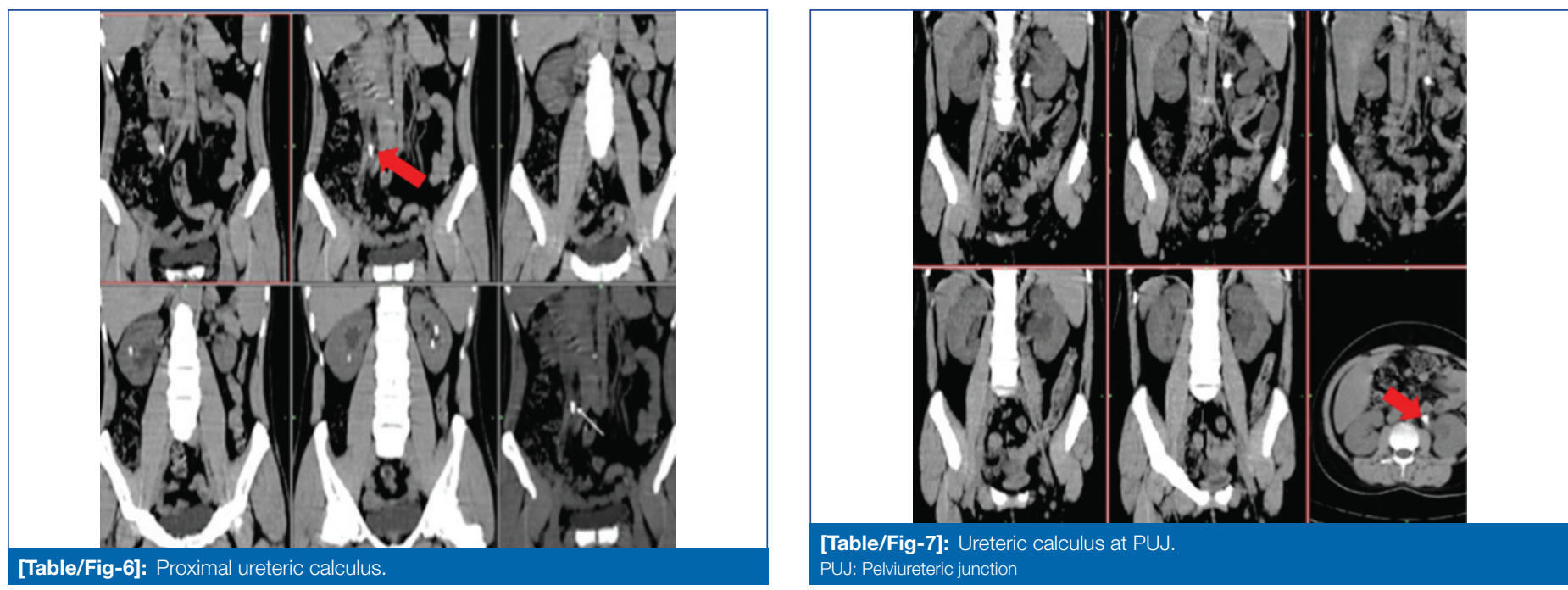

\begin{tabular}{|c|c|c|c|c|c|c|c|c|c|}
\hline \multirow[b]{2}{*}{ Region } & \multirow[b]{2}{*}{ Side } & \multirow{2}{*}{$\begin{array}{l}\text { Mean } \\
(\mathrm{mm})\end{array}$} & \multirow{2}{*}{$\begin{array}{l}\text { Std. deviation } \\
(\mathrm{mm})\end{array}$} & \multirow[b]{2}{*}{$\mathrm{t}$} & \multirow[b]{2}{*}{$\mathrm{p}$-value } & \multirow[b]{2}{*}{ Mean difference } & \multirow[b]{2}{*}{ Std. error difference } & \multicolumn{2}{|c|}{$95 \%$ Confidence interval of the difference } \\
\hline & & & & & & & & Lower & Upper \\
\hline \multirow{2}{*}{ PUJ } & Right & 10.11 & 3.259 & \multirow{2}{*}{-1.13} & \multirow{2}{*}{0.259} & \multirow{2}{*}{-0.94737} & \multirow{2}{*}{0.83337} & \multirow{2}{*}{-2.607} & \multirow{2}{*}{0.7131} \\
\hline & Left & 9.69 & 3.970 & & & & & & \\
\hline \multirow{2}{*}{ Proximal ureter } & Right & 7.01 & 1.970 & \multirow{2}{*}{-0.267} & \multirow{2}{*}{0.790} & \multirow{2}{*}{-0.10526} & \multirow{2}{*}{0.39419} & \multirow{2}{*}{-0.8907} & \multirow{2}{*}{0.6801} \\
\hline & Left & 6.82 & 1.421 & & & & & & \\
\hline \multirow{2}{*}{ UEIV } & Right & 5.91 & 1.749 & \multirow{2}{*}{0.388} & \multirow{2}{*}{0.699} & \multirow{2}{*}{0.15789} & \multirow{2}{*}{0.40667} & \multirow{2}{*}{-0.6524} & \multirow{2}{*}{0.9682} \\
\hline & Left & 6.12 & 1.795 & & & & & & \\
\hline \multirow{2}{*}{ Distal ureter } & Right & 4.82 & 1.41421 & \multirow{2}{*}{1.745} & \multirow{2}{*}{0.089} & \multirow{2}{*}{1.60526} & \multirow{2}{*}{0.91977} & \multirow{2}{*}{-0.25671} & \multirow{2}{*}{3.4672} \\
\hline & Left & 4.56 & 1.26362 & & & & & & \\
\hline \multirow{2}{*}{ VUJ } & Right & 3.34 & 0.02855 & 0107 & קח & 0000101 & 001010 & (200501 & 001530 \\
\hline & Left & 3.32 & 0.03104 & & 0.020 & 1 & 0.07010 & $0.0<0<1$ & 0.07000 \\
\hline
\end{tabular}

[Table/Fig-8]: Comparison of the mean size of ureteric stones between the two sides.

Student's $t$ test: Significance level 0.05); PUJ: Pelviureteric junction; UEVV: Ureter at the level of external lliac vessels; VUJ: Vesicoureteric junction

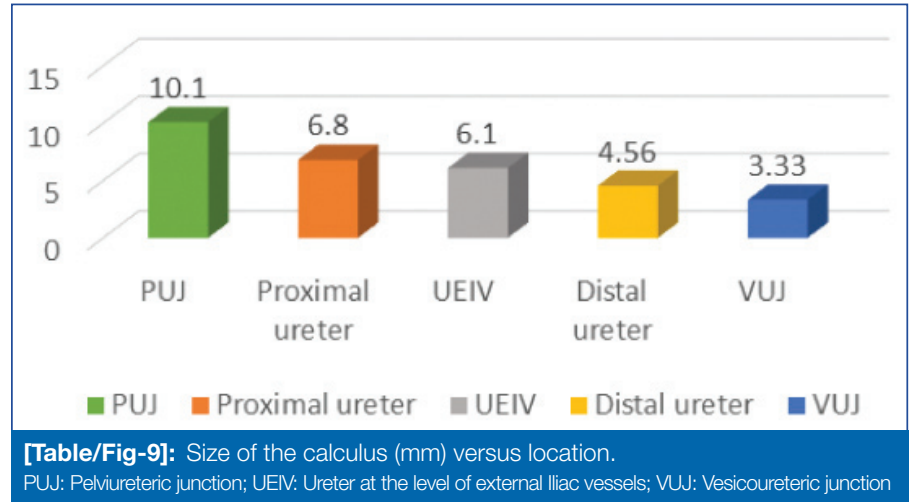

\section{DISCUSSION}

In the current study, the peak incidence of ureteric stones in males and females was in the $4^{\text {th }}$ and $5^{\text {th }}$ decade respectively. Several authors have witnessed the maximum incidence of urinary calculi between 30 to 50 years of age [8-13]. The current study is in agreement with same, with mean age of the patients being 41 years. The occurrence of ureteric stones in post-menopausal women has been attributed to urinary tract infections and a low dietary intake of magnesium and calcium [14,15]. The sex incidence ratio of ureteric calculi in the current study was 1.4:1. Jeevaraman $S$ et al., noted that the sex ratio of ureteric calculi was 1.7:1 [16]. Others have observed sex incidence ranging between $1: 1$ to $3: 1[17,18]$. The probable reason to this variation could stem from the factors like higher dietary intake of protein, hyperuricaemia and larger BMI [19].

There is no standardised way of ascertaining the size of a calculus. However, presence of a strong association between the stone width and length have suggested that each of the two can be utilised as a predictor for its passage [20]. However, it is of prime importance that whatever the selected criteria, it needs to be used consistently. In this study, the ureteral stone was measured by its width [7].

Calculi formation could result from supersaturation of urine by calcium or uric acid. It could also result because of the formation of Randall plaques [21]. In the current study, renal stones were observed frequently on the same side of the ureteric stones. This only underscores the fact that ureteral stones are mostly renal in origin. This study revealed the size of the stones regress as we proceed from the proximal to the distal part of the ureter.

In this study, majority of the stones were located at the VUJ (41\%), followed by the proximal ureter $(27 \%)$, the distal ureter was narrower. Observations made by Eisner $\mathrm{BH}$ et al., also suggested the same [22].

The ureteric stones in the current study were observed more often on the right side. Jeevaraman $S$ et al., documented equal distribution of calculi in the right and left sides of the ureter with no specific laterality [16]. However, Drach and Segura [23] and Higgins [24] cited a 55\% and $53 \%$ predilection to the left respectively. However, this study did not witness any statistically significant variation in the mean diameter of the right and left ureter. The mean ureteric diameter of this study was larger in comparison to the observations made by Zelenko $\mathrm{N}$ et al., [25]. The reason for the variations could be attributed to the peristalsis. A study has elucidated that ureteral stones pass more often on the left side [6]. A possible anatomical explanation could stem from the fact that the left ureter provide better peristalsis in comparison to the right which are adherent to the peritoneum as suggested by Foungaristos $S$ et al., [26].

The observations thus made may be pivotal in managing ureteral stones and in comprehending the ureteral anatomy. It is widely agreed that the location of the stone and size is an important predictor of stone passage. 


\section{Limitation(s)}

As the study was retrospective, the follow-up of these patients was not possible. Simple visual estimation on non-enhanced CT image was used for measurements as there is no standardised method available for ureteric stone size measurement while using noncontrast enhanced computed tomography. Possible variations in measurements due to ureteral peristalsis need to be considered.

\section{CONCLUSION(S)}

The pelvi-ureteric junction and the ureter corresponding to the external iliac vessel level are not frequent loci of ureteric stones. VUJ was observed to be the commonest site of ureteric stones. Ureteric stones more frequently observed on the right side. However, there was no significant difference in the diameters of the ureters of the both the sides. The smaller the stones, the closer they are to VUJ.

No significant sex related difference in the mean diameter of the ureteric stones was witnessed. This study provides an insight into the location and size of the ureteric calculi that would be essential for selection of appropriate line of intervention and treatment modality as well as in further understanding ureteral anatomy.

\section{REFERENCES}

[1] Snell RS. Clinical Anatomy. $7^{\text {th }}$ Edition, Lippincott Williams \& Wilkins, 2004, pp. 478-562

[2] Moore KL. Clinically oriented Anatomy, $3^{\text {rd }}$ Edition, Williams \& Wilkins 1992 , pp. 501-635.

[3] Song DW, Jeong TY, Lee SI, Kim DJ. Predicting factors for spontaneous passage of ureteral calculi based on unenhanced helical CT findings. Korean J Urol. 2008;49:1094-99. doi:10.4111/KJU.2008.49.12.1094

[4] Sandegard E. Prognosis of stone in the ureter. Acta Chir Scand.1956;(Suppl 219):01-67.

[5] Ueno A, Kawamura T, Ogawa A, Takayasu H. Relation of spontaneous passage of ureteral calculi to size. Urology. 1977;10:544-46. doi: 10.1016/00904295(77)90097-8.

[6] Kim BS, Hwang IK, Choi YW, Namkung S, Kim HC, Hwang WC, et al. Lowdose and standard-dose unenhanced helical computed tomography for the assessment of acute renal colic: Prospective comparative study. Acta Radiol. 2005;46(7):756-63.

[7] Nadler RB, Stern JA, Kimm S, Hoff F, Rademaker AW. Coronal imaging to assess urinary tract stone size. J Urol. 2004;172(3):962-64.
[8] Bailey RR, Dann E, Greenslade NF, Little PJ, McRae CU, Utley WL. Urinary stones: A prospective study of 350 patients. N Z Med J. 1974;79(516):961-65.

[9] Stamatelou KK, Francis ME, Jones CA, Nyberg LM, Curhan GC. Time trends in reported prevalence of kidney stones in the United States: 1976-1994. Kidney Int. 2003;63(5):1817-23.

[10] Hesse A, Brändle E, Wilbert D, Köhrmann KU, Alken P. Study on the prevalence and incidence of urolithiasis in Germany comparing the years 1979 vs. 2000. Eur Urol. 2003;44(6):709-13

[11] Trinchieri A, Coppi F, Montanari E, Del Nero A, Zanetti G, Pisani E. Increase in the prevalence of symptomatic urinary tract stones during the last ten years. Eur Urol. 2000;37(1):23-25.

[12] Stamatiou KN, Karanasiou VI, Lacroix RE, Kavouras NG, Papadimitriou VT, Chlopsios C, et al. Prevalence of urolithiasis in rural Thebes, Greece. Rural Remote Health. 2006;6(4):610.

[13] Kim H, Jo MK, Kwak CK, Park SK, Yoo KY, Kang D, et al. Prevalence and epidemiologic characteristics of urolithiasis in Seoul, Korea. Urology. 2002;59(4):517-21.

[14] Hall WD, Pettinger M, Oberman A, Watts NB, Johnson KC, Paskett ED, et al. Risk factors for kidney stones in older women in Southern United States. Am J Med Sci. 2001;322(1):12-18.

[15] Das P, Gupta G, Velu V, Awasthi R, Dua K, Malipeddi H. Formation of struvite urinary stones and approaches towards the inhibition-A review. Biomed Pharmacother. 2017;96:361-70. doi: 10.1016/j.biopha.2017.10.015.

[16] Jeevaraman S, Selvaraj J, Mohammed N, Niyamathullah. A study on ureteric calculi. International Journal of Contemporary Medical Research. 2016;3(10):2969-72

[17] Safarinejad MR. Adult urolithiasis in a population-based study in Iran: Prevalence, incidence, and associated risk factors. Urol Res. 2007;35(2):73-82.

[18] Fujita K. Epidemiology of urinary stone colic. Eur Urol. 1979;5(1):26-28.

[19] Wang S, Zhang Y, Zhang X, Tang Y, Li J. Upper urinary tract stone compositions: the role of age and gender. Int Braz J Urol. 2020;46(1):70-80.

[20] Jendeberg J, Geijer H, Alshamari M, Cierzniak B, Lidén M. Size matters: The width and location of a ureteral stone accurately predict the chance of spontaneous passage. Eur Radiol. 2017;27(11):4775-85.

[21] Alelign T, Petros B. Kidney stone disease: An update on current concepts. Adv Urol. 2018;2018:3068365. Published 2018 Feb 4. doi:10.1155/2018/3068365.

[22] Eisner BH, Reese A, Sheth S, Stoller ML. Ureteral stone location at emergency room presentation with colic. J Urol. 2009;182(1):165-68.

[23] Drach GW. Urinary lithiasis Chap 22 in Campells Urology. Harrison JH, et al (editors) Saunders; 1978: 779-878.

[24] Higgins CC. Factors in recurrence of renal calculi. JAMA. 1939;113(16):1460-65.

[25] Zelenko N, Coll D, Rosenfeld AT, Smith RC. Normal ureter size on unenhanced helical CT. AJR Am J Roentgenol. 2004;182(4):1039-41.

[26] Foungaristos S, Kavouras A, Perimenis P. Predictors for spontaneous stone passage in patients with renal colic secondary to ureteral calculi. Int Urol Nephrol. 2012;44(1):71-79.

PARTICULARS OF CONTRIBUTORS:

1. Associate Professor, Department of Anatomy, Shri Sathya Sai Medical College and Research Institute, Sri Balaji Vidyapeeth-Deemed to be University, Chennai, Tamil Nadu, India.

2. Assistant Professor, Department of Microbiology, Indira Medical College and Hospital, Thiruvallur, Tamil Nadu, India.

3. Professor and Head, Department of Anatomy, Shri Sathya Sai Medical College and Research Institute, Sri Balaji Vidyapeeth-Deemed to be University, Chennai, Tamil Nadu, India.

4. Assistant Professor, Department of Anatomy, Shri Sathya Sai Medical College and Research Institute, Sri Balaji Vidyapeeth-Deemed to be University, Chennai, Tamil Nadu, India

NAME, ADDRESS, E-MAIL ID OF THE CORRESPONDING AUTHOR:

Kafeel Hussain,

Door No.11, Plot No. 58, $5^{\text {th }}$ Cross Street, Rajalakshmi Nagar, Velachery,

Chennai, Tamil Nadu, India

E-mail: akafeelhussain@gmail.com
PLAGIARISM CHECKING METHODS: [Jain Het al.]

- Plagiarism X-checker: Aug 01, 2020

ETYMOLOGY: Author Origin

- Manual Googling: Nov 18, 2020

- iThenticate Software: Jan 05, 2021 (21\%)

\section{AUTHOR DECLARATION:}

- Financial or Other Competing Interests: None

- Was Ethics Committee Approval obtained for this study? Yes

- Was informed consent obtained from the subjects involved in the study? Yes

- For any images presented appropriate consent has been obtained from the subjects. Yes

Date of Submission: Jul 27, 2020 Date of Peer Review: Oct 03, 2020 Date of Acceptance: Nov 20, 2020 Date of Publishing: Apr 01, 2021 